\title{
Benefits of recording images during video laryngoscopy for early detection of oropharyngeal and laryngeal lesions: implications for "inattentional blindness"
}

\author{
André A. J. Van Zundert, MD, PhD, FRCA, EDRA, FANZCA • \\ Kerstin H. Wyssusek, MBBS, PhD, FAAnaesth, FANZCA • \\ Keith B. Greenland, MBBS, MD, FANZCA, FHKAM
}

Received: 12 March 2018/Revised: 16 March 2018/Accepted: 16 March 2018/Published online: 2 April 2018

(C) Canadian Anesthesiologists' Society 2018

The introduction of video laryngoscopy has significantly improved the success rate of difficult airway management. It offers better options for visual instrumentation of the airway and esophagus and provides a four times larger vertical visual angle of view $\left(60^{\circ}\right)$ of the oropharynx compared with conventional direct laryngoscopy $\left(15^{\circ}\right){ }^{1}$

The ability of video laryngoscopes to acquire and store images and/or video clips provides an important underrecognized function. The anesthesiologist may observe a wide array of asymptomatic lesions during routine laryngoscopy performed for tracheal intubation. Images and video clips can be stored in the patient's medical record for possible referral to the appropriate specialist. This practice is similar to that of gastroenterologists, who regularly retain procedural images for review and planning purposes.

Examples of such pathological lesions include cysts in the vallecula, tumours of the epiglottis and posterior pharynx, vocal cord granulomas, and even tonsillar leukoplakia (see Figure for details). It is vital that some of these abnormalities are detected and managed as early as possible as treatment delays may adversely affect outcome and survival. ${ }^{2}$

A. A. J. Van Zundert, MD, PhD, FRCA, EDRA, FANZCA ( $\square$ )

K. H. Wyssusek, MBBS, PhD, FAAnaesth, FANZCA

Department of Anaesthesia \& Perioperative Medicine, Royal Brisbane \& Women's Hospital \& The University of Queensland,

Brisbane, Australia

e-mail: vanzundertandre@gmail.com

K. B. Greenland, MBBS, MD, FANZCA, FHKAM

Department of Anaesthesia \& Pain Management, Wesley

Hospital, Brisbane, Australia
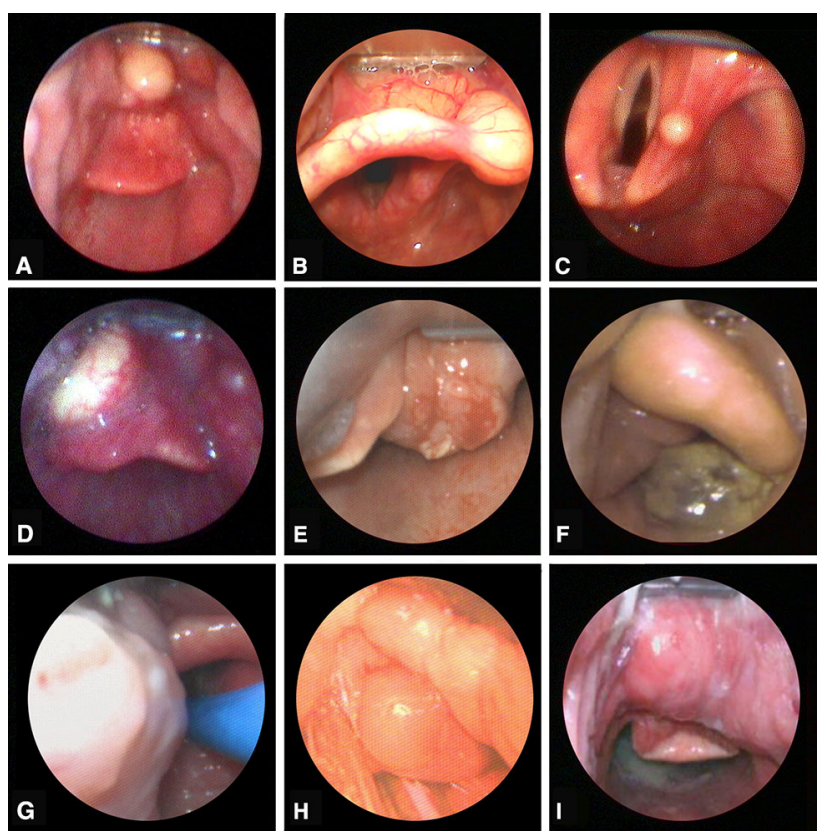

Figure Anesthesiologsists may play a role in documenting and referring some airway pathology for diagnosis and treatment after unexpectedly detecting them during routine video laryngoscopy. Examples of pathological lesions that we have recently detected using this technique include cysts in the A) vallecula, B) epiglottis, and C) aryepiglottic fold; tumours of the D) posterior epiglottis, E) cuneiform cartilage, and F) posterior pharynx; G) tonsillar leukoplakia; H) a vocal cord granuloma; and I) a vallecular abscess. All of these malformations were incidental discoveries in patients without signs or symptoms. Approval for publication of these images with a waiver for specific patient consent was granted by the Royal Brisbane \& Women's Hospital Human Research Ethics Committee (HREC/18/ QRBW/145; 15 March 2018)

As the anesthesiologist is often focused on securing the airway, however, these pathological lesions may not be found due to a phenomenon known as "inattentional 
blindness, ${ }^{3}$ which occurs when an operator fails to notice a visible, but unexpected, object when engaged in a specific task. In this case, the anesthesiologist is focused on intubating the trachea and fails to see a nearby airway lesion. Review of video laryngoscopic images or videos may provide objective evidence of airway lesions that have been missed by inattentional blindness.

We posit that recording/review of these images should be routine. If not currently possible, we suggest that anesthesiologists consider petitioning their institutions to provide the needed technology to make this additional tool a reality, perhaps even incorporating it into the hospital's electronic registration system.

Conflicts of interest None declared.

Editorial responsibility This submission was handled by Dr. Hilary P. Grocott, Editor-in-Chief, Canadian Journal of Anesthesia.
Financial support Support was provided solely from institutional and/or departmental sources.

\section{References}

1. Van Zundert A, Pieters B, Doerges V, Gatt S. Videolaryngoscopy allows a better view of the pharynx and larynx than classic laryngoscopy. Br J Anaesth 2012; 109: 1014-5.

2. Cheraghlou $S$, Kuо $P$, Judson $B L$. Treatment delay and facility case volume are associated with survival in early-stage glottis cancer. Laryngoscope 2017; 127: 616-22.

3. Mack A. Inattentional blindness: looking without seeing. Curr Dir Psychol Sci 2003; 12: 180-4. 